\title{
Estetika fragmenta kot ključ za razumevanje Schumannove Hausmusik
}

\author{
The Aesthetic of the Fragment as a Key to \\ Understanding Schumann's Hausmusik
}

Ključne besede: Robert Schumann, fragment, romantična estetika, samospevi, klavirska glasba

\section{IZVLEČEK}

Schumannova glasba - predvsem tista, ki je nastala nekako do leta 1840 - velja danes za paradigmo romantične glasbene umetnosti. Skladateljevo navdušenje nad sočasno romantično literaturo ni ostalo zgolj na ravni recepcije in posameznih literarnih poskusov, temveč je močno zaznamovalo tudi njegovo glasbeno poetiko. Ta pa brez poznavanja estetike (literarnega) fragmenta ostaja zgolj področje številnih interpretativnih vrzeli.
Keywords: Robert Schumann, the fragment, the romantic aesthetic, lieder, piano music

\section{ABSTRACT}

Schumann's music - especially the music composed until approximately 1840 - is today regarded as a paradigm of romantic instrumental music. The composer's enthusiasm for the romantic literature of his time did not remain simply on the level of reception and isolated literary experiments, it strongly influenced his musical poetics. Without a knowledge of the aesthetic of the (literary) fragment, however, the latter remains merely a field of numerous interpretive gaps. 


\section{"Estetika ene je estetika drugih umetnosti; samo material je različen."}

Schumannov stavek, ki sporoča "Zanesenjaško predstavo o 'eni' umetnosti ${ }^{2}$, lahko razumemo ne zgolj kot tezo 19. stol., temveč tudi kot eno temeljnih idej romantike. Carl Dahlhaus ga uporablja kot argument pri utemeljevanju metafizike lepega in s tem tudi estetike. Pri tem poudarja, da gre misel razumeti kot ločevanje med umetnostjo (poezijo) in obrtjo (prozo). ${ }^{3}$ Meni še, da Schumannovo pojmovanje umetnosti izhaja iz estetike Jeana Paula, enega prvih literarnih romantikov, ki so udejanjili odpor do klasicističnih oblikovnih teženj v korist prihajajočega subjektivizma. ${ }^{4}$

Zgornji navedek je prav tako mogoče opaziti v Taruskinovi interpretaciji Schumannove ustvarjalne poetike. Ta ga umešča v kontekst razmerja med besedo in glasbo, ki v skladateljevi (predvsem klavirski, pa tudi samospevni) govorici kaže izvirno sintezo obeh medijev. Še več: Taruskin govori v zvezi s Schumannom o 'literarni glasbi'. ${ }^{5}$ To na prvi pogled sicer zelo problematično oznako ${ }^{6}$ argumentira s tezo Schumannovega biografa in zgodovinarja romantike Johna Daveria, da bi bil za Schumanna ideal "glasba kot literatura". Po Taruskinovem mnenju misli ne gre razumeti kot glasbo z določeno literarno zgodbo ali 'programom', temveč kot glasbo z 'intelektualno vsebino'. Kot pravi, je Schumann svoje poslušalce spodbudil, da so v glasbi prepoznavali več kot zgolj čutni dražljaj, da so v njej iskali miselno in duhovno angažiranost, ki so jo lahko našli v literaturi. ${ }^{7} \mathrm{~S}$ tem naj bi se skladatelj zoperstavil tudi razsvetljenski misli, ki je pripisovala glasbi status zabave in ne kulture.

Obema interpretacijama uvodnega navedka (Dahlhausovemu umeščanju v kontekst zgodovinskega risa estetike glasbe in Taruskinovem zagovarjanju 'literarne glasbe') je skupno, da Schumannovo estetiko in poetiko tesno povezujeta $z$ literarno umetnostjo skladateljevega časa.

Bayreuthski pesnik Jean $\mathrm{Paul}^{8}$ je predstavljal kultno osebnost svojega časa, uspeh njegovih del pa je postavil v senco celo samega Goetheja. V tej evforiji jeanpaulizma je odraščal tudi Schumann, ki se ga je ta literarna 'moda' na poseben način dotaknila. Tako je ne le prebral večino del Jeana Paula, temveč se je tudi sam preizkušal kot literat v pesnikovem slogu. Ali je šlo pri tem za duhovno sorodnost z zanesenjaškim pesnikom in njegovo razdvojeno naravo (s katero se je Schumann lahko še posebej identificiral), ni toliko pomembno, kot je pomembno, da se je ob estetiki Jeana Paula izoblikovala Schumannova ustvarjalna poetika (predvsem poetika klavirske glasbe in samospeva). Kot pravi Dahlhaus: "Schumannova klavirska dela vsebujejo poezijo, prežeto z duhom Jeana Paula, poezijo literarnih in tudi avtobiografskih aluzij, motov in zgovornih naslovov, za katere se včasih zdi, da pomenijo več kot dejansko govorijo».?

Peter Rummenhöller ponazarja ob naslovih Schumannovih klavirskih del navzočnost literarnih motivov Jeana Paula: motiv maškarade kot simbol nejasnega vrvenja sveta, motiv maske kot simbol problematike romantične identitete, motiv dvojčkov kot simbol dveh nasprotij $\mathrm{v}$ človeku ipd. ${ }^{10} \mathrm{~V}$ Schumannovem klavirskem opusu (ne gre pozabiti, da je skladatelj prvih 23

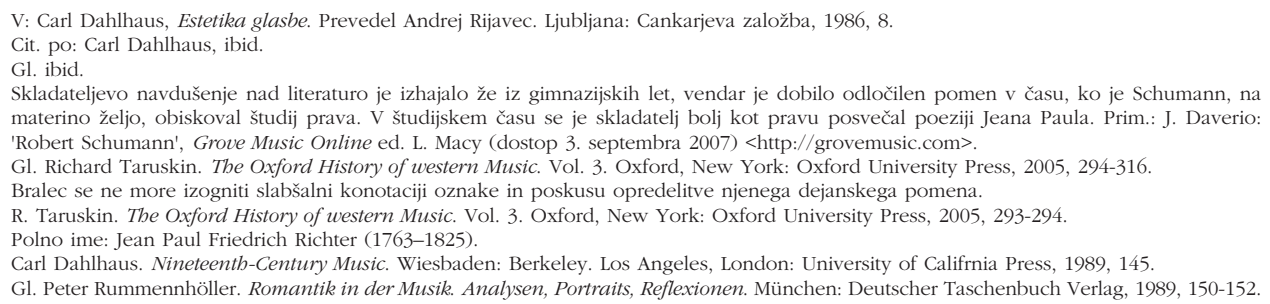


opusov namenil izključno klavirski glasbi) obstajajo, po besedah Rummenhöllerja, namigi tudi na ustvarjalnost E. T. A. Hoffmanna. Zelo majhna verjetnost je, da bi lahko imela umetnika dveh različnih generacij osebne stike. Kljub temu pa je znana neverjetna podobnost med njima. O obeh lahko govorimo kot o tipu umetnika z več talenti: oba sta vpisala pravo, la da ga je Hoffmann uspešno končal, Schumann pa prekinil, oba sta se ukvarjala s pesništvom in pisanjem o glasbi (Schumann je kot ustanovitelj, urednik in pisec revije 'Neuen Zeitschrift fur Musik' dosegel, da je postala povsod priznana), oba sta delovala kot kapelnika in skladatelja. ${ }^{11}$ Zato ne presenečajo številne aluzije, kot denimo naklonjenost bizarnemu in demonskemu ali pa nagnjenost k tajnemu združenju, ki ju lahko opazimo tako v literarnem delu E. T. A. Hoffmanna kot publicističnem in glasbenem delu R. Schumanna.

Da pa Schumannovo spogledovanje z romantično literaturo ni ostalo zgolj na ravni intimnega doživljanja literarnega miljeja, lahko razberemo iz teh Schumannovih stavkov: "Zu Ende des Jahres 1833 fand sich in Leipzig, allabendlich und wie zufällig, eine Anzahl meist jüngerer Musiker zusammen, zunächst zu geselliger Versammlung, nicht minder aber auch zum Austausch der Gedanken über die Kunst, die ihnen Speise und Trank des Lebens war, - die Musik. Man kann nicht sagen, dass die damaligen Zustände Deutschlands sehr erfreulich waren (...) Da fuhr denn eines Tages der Gedanke durch die jungen Brauseköpfe: lasst uns nicht mussig zusehen, greift an, dass es besser werde, greift an, dass die Poesie der Kunst wieder zu Ehren komme. So entstanden die ersten Blätter einer neuen Zeitschrift für Musik. (...) «12 Odlomek Schumannovega pričevanja sugerira, da so srečanja glasbenikov na ravni dialogov postajala plodna osnova pri izmenjavi glasbenih, literarnih in tudi filozofskih idej. S tem postane razumljivo, da je tudi glasba sama začela zrcaliti duha kulturnega miljeja, v katerem je nastajala.

Dahlhaus označuje Schumannovo glasbo, nastalo nekako do 1840. leta (klavirske miniature in samospevi) kot Hausmusik ali glasbo za poznavalce. ${ }^{13}$ Ta je torej nastajala v ozkem krogu izbrane družbe, kulturnem okolju, zaznamovanem z romantično estetiko, ki je skladateljevo govorico tudi razumelo. To okolje se je kazalo v sprejemanju novih idej in literarnih motivov, simbolov kot tudi naslovov skladb, v pripisovanju statusa poezije glasbi, torej na ravni estetskega dojemanja glasbene umetnosti. To dokazuje tesno povezanost Schumannove ustvarjalnosti z literaturo, ne pa tudi neposrednega vdora literature $\mathrm{v}$ glasbo.

Pri tem se poraja vprašanje, ali lahko najdemo konkretno, oprijemljivo osnovo, ki bi lahko bila skupna tako glasbi kot literaturi, oz. ali bi glasba lahko še bolj neposredno zrcalila literaturo, kot je bilo mogoče doslej razbrati iz razprave.

V svoji razpravi Rummenhöller omenja, da je bistvena značilnost romantičnega svetovnega nazora in deloma tudi romantične estetike fragment. Kot pravi, se protislovje vsega romantičnega mišljenja - med neskončnostjo in sedanjostjo, utopijo in resničnostjo - uresničuje $\mathrm{v}$ estetskem programu fragmenta, saj bi lahko bila neskončnost snovi sicer le omejeno predstavljena v konkretni, končni obliki. Prav zato se po njegovem mnenju romantično oblikovanje izogiba eksaktnemu začetku in eksaktnemu koncu, saj bi s tem postala forma "brezmejna" ("entgrenzt“). ${ }^{14}$

Kako se estetika fragmenta zrcali v samem glasbenem delu, Rummenhöller ne pojasnjuje, vendar z analizo Schumannovega klavirskega dela "Warum?" nedvomno sugerira interpretacijo, ki prestopa meje zgolj kompozicijskotehnične razlage oz. že vstopa na področje romantične estetike.

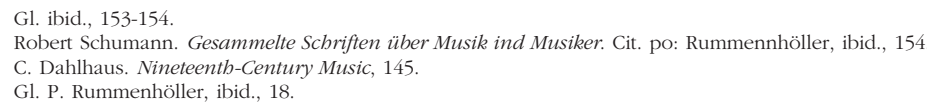


Analizo skladbe začenja s stavkom: "Skladba nima ne začetka ne konca." (Das Stück hat keinen Anfang und keine Ende“. $)^{15}$ Pri tem ima v mislih začetek, ki bi ga glede na značaj in funkcijo težko opredelili kot začetek, kakršnega je poznala dotedanja klasicistična tradicija: raba stranske dominante že v prvem taktu daje misliti, da glasba preprosto "od nekod vstopa" in potem (tisto, kar naj bi označili kot zaključek) "zapusti prizorišče dogajanja". Poleg linearnega načina mišljenja kot prepletanja prekrivajočih se glasov izstopa pogosta verižna raba dominant. Ta povzroča nenehno gibanje glasbenega toka, ki pa v izkušnji poslušalca vodi do odlašanja pričakovane razveze. Nenehno zamikanje pričakovane tonike $\mathrm{z}$ verižno rabo dominant se $\mathrm{v}$ zavesti poslušalca manifestira kot neizpolnjeno pričakovanje ali tudi hrepenenje. $\mathrm{V}$ tem harmonsko-tehničnem prijemu lahko po mnenju Rummenhöllerja prepoznamo romantično idejo neskončnosti. Če prvi akord skladbe (dominanto dominante) interpretiramo kot nadaljevanje nečesa imaginarno že obstoječega, nizanje dominant kot odlaganje razrešitve, sklepne takte ne kot "popoln", temveč "neskončni zaključek", sintaktično členjenje (nihanje med simetrijo in asimetrijo) kot spoznanje romantične preudarnosti, hitro ugotovimo, da skladba razgrinja nekatere značilnosti romantičnega mišljenja in občutenja. Izkaže se, da so te neločljivo vpete v tehnične prijeme Schumannove poetike.

Rummenhöllerjeva interpretacija sicer na izviren način razkriva uresničitev romantične estetike v Schumannovem klavirskem delu, vendar ne pojasnjuje, v kakšni korelaciji bi lahko bila literarni fragment (ki ga v uvodu svoje razprave označuje kot bistveno značilnost romantične estetike) in Schumannova klavirska miniatura.

Da je mogoča eksplicitna razlaga povezanosti med fragmentom kot literarno obliko in Schumannovo poetiko samospevov ter klavirskih del, dokazuje Charles Rosen v svojem prodornem delu The Romantic Generation. ${ }^{16} \mathrm{Ob}$ pojmovanju jenske romantične šole ponazarja oblikovne in estetske lastnosti literarnega fragmenta, pri tem pa se sklicuje na fragmente Friedricha Schlegla. Kot pravi, je Schlegel že sam ponudil definicijo oblike (fragmenta), ki pa je tudi sama po sebi eden od 451 'Fragmentov', natisnjenih v literarnem časopisu 'Athenäum' ${ }^{17}$ :

"Ein Fragment muss gleich einem kleinen Kunstwerke von der umgebenden Welt ganz abgesondert und in sich selbst vollendet sein wie ein Igel."18

"Fragment mora biti kot majhna umetnina povsem ločen od sveta, ki ga obdaja, in sklenjen sam v sebi tako kot jež." ${ }^{19}$

Po mnenju Rosena je oblika fragmenta jasno definirana, pa vendarle nejasna, ko skušamo določiti njene meje. In čeprav je fragment ločen od preostalega sveta, namiguje na oddaljeno perspektivo.

V literarnih razlagah lahko preberemo, da s fragmentom kot duhovito, dvoumno domislico sporoča Schlegel na videz protislovna stališča, v katerih pa gre prepoznati izrazito romantično potezo. ${ }^{20}$ Njegova dinamična, 'subjektivistična' narava omogoča "vzdrževanje napetosti med idejo in resničnostjo, neskončnostjo in končnostjo", zato se kaže kot primeren 'medij' kritiške misli.

Virk piše, da se je Friedrich Schlegel, zvest univerzalističnemu duhu romantike oziroma svoji lastni definiciji le-te, poskusil v domala vseh zvrsteh pisanja: bil je bolj slab pesnik in dramatik, a zanimiv romanopisec, izjemen pisec aforizmov, kritik in esejist, prenikav filozof, filolog, estetik, celo pisec zgodovinskih, političnih in teoloških razprav. Njegova posebnost je

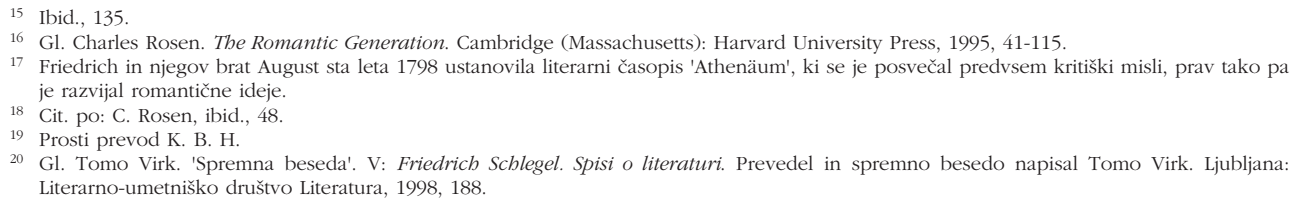

20 Gl. Tomo Virk. 'Spremna beseda'. V: Friedrich Schlegel. Spisi o literaturi. Prevedel in spremno besedo napisal Tomo Virk. Ljubljana: Literarno-umetniško društvo Literatura, 1998, 188. 
bila živahen temperament, bržkone posledica notranje razdvojenosti, ki je pri njem vodila $\mathrm{v}$ aforistično, paradoksno pisateljsko obliko in posebno vrsto romantične ironije. Schlegel je bil kar najgloblje usidran v duha časa, zato upravičeno velja - kljub protislovnostim, ki včasih kažejo na restavracijsko miselnost - za paradigmatskega predstavnika romantike. ${ }^{21}$

Aforistično naravnana literarna oblika pa je imela, kot pravi Rosen, svojo tradicijo že v 17. in 18. stoletju - zlasti v maksimah ${ }^{22}$ La Rochefoucaulda in La Bruyèreja. Z romantičnim fragmentom so se "meje besednih pomenov začele širiti, to pa pomeni, da so hkrati pomenile več, kot so dejansko označevale «. ${ }^{23}$ Čeprav se je težnja po objavljanju fragmentov začela kazati že nekaj desetletij pred nastankom fragmentov Friedricha Schlegla (eno najbolj znanih del nemške literature, Goethejev Faust, je bilo prvič objavljeno leta 1790 kot fragment), je ta - s tem da je namignil, da je prav fragmentarno stanje njegova pozitivna lastnost ("Mnoga dela starih so postala fragmenti. Mnoga dela novejših so to že takoj ob nastanku. ${ }^{24}$ ) - obliki zagotovil trdnejšo osnovo. Za Schleglov umetniški nazor je bila klasicistična estetika nesprejemljiva, zato je koncept 'lepote' zamenjal z dinamičnim konceptom nepopolnosti, to pa pomeni, da je njegova estetika zagovarjala novo in progresivno pojmovanje umetnosti. ${ }^{25}$

Vsak fragment je oz. bi moral biti zaokrožena forma: nepopolna je njegova vsebina - oz. z vsakim branjem se ta razvija naprej. Zato sproža proces, katerega zaključek ni viden. Pritrdimo lahko, da je romantični fragment zaprta struktura, vendar pa je njegov zaključek zgolj zunanja oblika - čeprav ga je mogoče ločiti od preostalega sveta, pa implicira obstoj zunanjega - ne z referenco, temveč z lastno nestabilnostjo. ${ }^{26}$

Rosenove ugotovitve so nedvomno v skladu s tezo, da je "fragment (pol)literarna forma, ki je osredinjena na trenutek izrekanja in že s svojo pojavnostjo zanika možnost v času obstojnega diskurzivnega sistema ". ${ }^{27}$ Ta miselni drobec je torej svojo romantično estetiko postopoma razpršil na vse strani literarnega izražanja (tudi na ustvarjalnost Jeana Paula in E. T. A. Hoffmanna), prav tako pa je ta pustila sledi v nekaterih drugih umetnostih. V glasbi bi lahko, po ugotovitvah Rummenhöllerja in Rosena, za najvidnejšega predstavnika estetike fragmenta označili prav Roberta Schumanna.

In kako se estetika fragmenta zrcali v Schumannovi tako imenovani Hausmusik?

Schumannovo navdušenje nad literarnim delom Jeana Paula in E. T. A. Hoffmanna ter njegovi literarni poskusi v jeanpaulovskem slogu so nedvomno pomenili poistovetenje ustvarjalnega kreda z romantično estetiko. Kot je ob analizi klavirske miniature potrdil Rummenhöller, se je ta kazala na semantični ravni tako oblike kot vsebine. Tisto vrzel, ki pa jo je izpustil most, ki povezuje estetiko fragmenta s konkretnimi kompozicijskoanalitičnimi izsledki - je temeljito razvozlal prav Rosen v omenjenem orisu.

Da je estetika fragmenta še posebej zaznamovala Schumannove cikle samospevov, je podrobno ponazoril ob analizi posameznih samospevov. Tako je domnevno samostojnost leteh, pa tudi pripadnost večji celoti argumentiral s stališča estetike fragmenta. Kot ugotavlja, so posamezni samospevi cikla na videz samostojne pesmi, a večinoma ne morejo biti izvedene

21 Gl. ibid., 191.

22 Maksima je kratka zgoščena misel s splošno vsebino. Do 17. stoletja je izraz maksima pomenil življenjsko vodilo ali načelo, ki v nekaj kratkih stavkih nedvoumno izraža določeno pravilo ali nauk. Nov pomen je maksimi dal La Rochefoucauld, ki je v svoji knjigi ljudi opominjal, da se za njihovimi maskami skrivajo strasti in pohlep. Z La Rochefoucauldom je postala maksima ne samo splošno načelo, ampak tudi vsak aforizem, ki je duhovit, paradoksalen ali presenetljivo zaostren. Gl. Djurdja Flere. 'Spremna beseda'. V: Francoski moralisti: Pascal, La Rochefoucauld, La Bruyere, Vauvenargues, Montesquieu, Chamfort, Rivarol. Prev. Bogo Stopar. Ljubljana: Mladinska knjiga 1977 , 162.

23 C. Rosen, ibid., 49-50.

24 Prevedel Tomo Virk. V: F. Schlegel, ibid., 21.

5 C. Rosen, ibid., 50.

Ibid., 51

27 Vanesa Matajc. 'Interakcija literature in teorije: od romantike do moderne'. V: Primerjalna književnost. 29/ posebna številka (2006), 125. 
samostojno. Če torej samospev (iz cikla) enačimo s fragmentom, ugotovimo, da njegova semantičnost presega 'povedano', zato postane izločanje iz konteksta vprašljivo. Novo semantičnost samospeva pa razkrivajo kompozicijskotehnični prijemi, ki prinašajo spremembe tradicije. To pa se ne nanaša zgolj na proces harmonskega gibanja (začetek, potek in zaključek) in dvoumnega sintaktičnega členjenja - kot ju je v prej omenjeni Schumannovi miniaturi že analitično razčlenil Rummenhöller - temveč tudi na novo razmerje med besedami in glasbo.

Romantična estetika je glasbi dodelila abstraktni model jezika, to pa pomeni, da je ni zgolj povzdignila na raven kulture, ji pripisala kategorije poetičnosti in botrovala emancipaciji instrumentalne glasbe, temveč je tudi, kot kaže umetnost samospeva pri Schumannu, temeljito preoblikovala razmerje med besedilom in glasbo. Razmerje med vokalom in inštrumentalno spremljavo je bilo v preteklosti jasno definirano, v začetku 19. stol. pa se je nekoliko zameglilo.

Rosen je mnenja, da so bile ideje Schleglovega kroga v Jeni - identificiranje glasbe z govorom in zavestjo samo - Schumannu znane. Te naj bi prevzel E. T. A. Hoffmann v svoji Kreisleriani. ${ }^{28}$

In kako se je to spremenjeno razmerje med nekoč estetsko neenakopravnima medijema uresničevalo v Schumannovih samospevih? Tradicionalno razmerje med pesmijo in spremljavo je preoblikoval skladatelj tako, da je celotna melodija (pesem) bodisi v klavirju bodisi prehaja iz melodije klavirja v glas, to pa pomeni, da je določena pričakovana (splošna) melodija uresničena v besedah le pretrgano oz. v presledkih. Če je bila ta znotraj vokala prej koherentna in sklenjena celota, je v Schumannovi poetiki doživela "nepopolno destrukcijo samostojnosti vokala". ${ }^{29}$ To pomeni, da je vokalna melodija izgubila samostojnost v pomenu razumljive strukture; ker pa melodija ni bila v celoti postavljena $\mathrm{v}$ inštrumentalni part, je bila njena samostojnost le deloma zatrta. Kot pravi Rosen, je prav to nepopolno zlitje besede in glasbe postalo eden temeljnih principov Schumannovega snovanja samospevov. Tovrstno zlitje besede (vokala) in glasbe (instrumentalne spremljave) pa je bilo lahko uresničeno le tako, da je glasba prevzela prednost in ne dominantne vloge.

In prav ta nenehna igra z negotovostjo - premeščanje poudarka z vokala na instrumentalno spremljavo in narobe - se ujema z estetiko fragmenta. Tako kot sega pomen dvoumne domislice čez meje 'povedanega', tako se tudi glasba nanaša na nekaj zunaj sebe. Čeprav se zdi oblika literarnega in glasbenega fragmenta 'od daleč' definirana, pa ob izostrenem pogledu postane zamegljena. Semantičnost obeh se kaže v ločenosti od preostalega sveta in vendarle oba sugerirata oddaljeno perspektivo, ki je njun cilj. To potrjuje tako Rummenhöllerjeva analiza Schumannove klavirske miniature kot Rosenovo razkrivanje spremembe tradicije samospeva.

Če skušamo pojasniti transfer z literarnega fragmenta na glasbenega, ugotovimo, da se narativnost literarnega fragmenta manifestira tako na semantični kot sintaktični ravni skladbe. Sintaksa kaže spremenjeno rabo kompozicijskih sredstev (harmonski jezik, členjenje struktur, razmerje med vertikalo in horizontalo), katerih pomenskost sugerira dvoumnost, nejasnost, odprtost. 'Brezmejnost' (Entgrenzung ${ }^{30}$ ) oblike - skladba brez primernega gramatikalnega (začetka in) zaključka - uteleša estetiko fragmenta tako, da njen pomen presega meje povedanega. Najočitneje se to potrjuje v razmerju med samospevom in ciklom, iz katerega ta izhaja. Podoben položaj razkriva tudi klavirska miniatura, bodisi kot samostojna entiteta bodisi kot del večjega cikla.

Da se narativni model fragmenta najočitneje manifestira v poetiki miniature in samospeva Roberta Schumanna, potrjujeta tako Rummenhöller kot Rosen. Pod izjemnim vplivom literature,

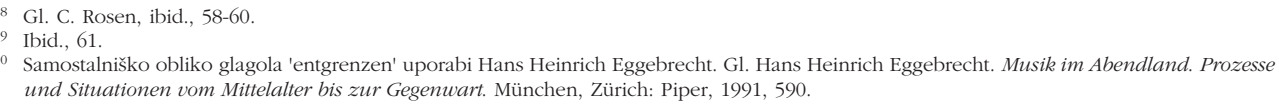


predvsem pa romantične estetike, s katero se je skladatelj poistovetil tako na osebni kot ustvarjalni ravni, je ujel originalnost in eksotično razsežnost oblike ter jo 'prevedel' v glasbeni jezik svojega časa.

V tem kontekstu postane tudi uvodni Schumannov citat še posebej zgovoren in pomenljiv. Po značaju aforizem, primerljiv z literarnimi fragmenti jenske romantične šole, lahko razumemo kot stičišče skladateljevega navdušenja nad literaturo in notranje potrebe po prenosu le-te v glasbo. Ta prenos pa ne pomeni glasbe $\mathrm{z}$ določeno literarno zgodbo ali programom, temveč uresničitev 'intelektualne vsebine', tiste, ki jo je postulirala romantična estetika ob prelomu stoletja.

Schumannov aforizem tako kaže poistovetenje skladateljeve umetniške esence z literarnim miljejem. Hkrati pa kot literarni fragment, formalno sicer zaprta struktura, namiguje na nekaj, kar presega meje 'izrečenega', na smisel, ki obstaja onstran meja zamegljene forme, da glasba ni več zgolj užitek, temveč se je (kot enakovredna literaturi in filozofiji) povzdignila na raven kulture.

\section{SUMMARY}

The article derives from Schumann's statement "the aesthetics of one art is that of the others too; only the materials differ", which Dahlhaus and Taruskin each established within their own interpretive domain: Dahlhaus placed it in the context of the historical outline of the aesthetics of music, and Taruskin in the context of the relationship of words and textless music in Schumann's piano pieces. Both interpretations share a common basis: that Schumann's aesthetic and poetics are closely connected with the literary art of the composer's era. It is known that Schumann grew up in the euphoria of Jean Paulism, and that he himself tried his hand at the poet's style in some literary experiments. The fact that romantic literature clearly marked the composer's musical poetics is evident from the discussion of Peter Rummenhöller, who illuminates the presence of the literary motives of Jean Paul in Schumann's piano works. He also determines that an essential characteristic of the romantic world view, and also partly of the romantic aesthetic, is the fragment. Precisely how the aesthetic of the fragment is reflected in the actual musical work is not clarified by Rummenhöller, but with his analysis of Schumann's piano work “Warum?' he undoubtedly suggests an interpretation that oversteps the border of compositional-technical explanation and enters the realm of the romantic aesthetic. In Charles Rosen's discussion, however, he demonstrates that it is possible to explicitly explain the connection between the fragment as a literary form and Schumann's poetics of lieder and of piano works. Rosen gives an historical outline of the literary fragment and defines its aesthetic, and by analysing certain of Schumann's works he illustrates how the aesthetic of the fragment is reflected on the compositional-technical level. Here the narrative nature of the literary fragment is manifested both on the semantic and syntactic levels of the compositions. At the same time, the demonstration of the transfer from literature to music becomes the key to the interpretation of the composer's musical poetics.

In the context of the entire discussion, the introductory quotation of Schumann becomes even more meaningful. Not only does it reveal the aesthetic of the composer's creative milieu and suggest the intersection of his enthusiasm for literature and his inner need to transfer this to music, but it is also itself a fragment. As such, it hints at something that surpasses the border of the "narrated"; namely, that music is no longer simply a pleasure, it has raised itself to the level of culture. 